\title{
Can power spectral analysis of heart rate variability identify a high risk subgroup of congestive heart failure patients with excessive sympathetic activation? A pilot study before and after heart transplantation
}

Andrea Mortara, Maria Teresa La Rovere, Maria Gabriella Signorini, Paolo Pantaleo, Gianni Pinna, Luigi Martinelli, Claudio Ceconi, Sergio Cerutti, Luigi Tavazzi

\begin{abstract}
Background and objectives-Autonomic dysfunction seems to be involved in the progression and prognosis of severe congestive heart failure. Parasympathetic activity can still be abnormal 4-8 weeks after haemodynamic improvement by heart transplantation. To identify patients in heart failure with a more pronounced neural derangement and to analyse the changes in sympathetic and parasympathetic activity soon after heart transplantation, spectral indices of heart rate variability were assessed in 30 patients in severe heart failure and in $\mathbf{1 3}$ patients after heart transplantation; a group of 15 age-matched subjects served as controls.
\end{abstract}

Methods and results-Heart rate variability was assessed by standard electrocardiography (ECG) in patients in heart failure and by oesophageal ECG in patients after heart transplantation. Compared with controls, the mean RR interval and total power were reduced in heart failure. The $\mathbf{3 0}$ patients showed two different patterns of heart rate variability: in 14 no power was detected in the low frequency band $(0 \cdot 03-0 \cdot 15 \mathrm{~Hz})$ (LF) and total power was mainly concentrated in the high frequency band $(0 \cdot 15-0.45 \mathrm{~Hz})$ (HF), whereas in the remaining 16 patients power in the LF band was increased and power in HF band was reduced compared with the controls. Patients with undetectable LF had a lower mean RR interval and total power (745(25) $v$ 864(36) ms, p < 0.05; 118(16) $v$ 902(202) $\mathrm{ms}^{2}, \mathrm{p}<0.001$ ), higher concentration of plasma noradrenaline $(635(75)$ $v 329(54) \mathrm{pg} / \mathrm{ml}, \mathrm{p}<0.05)$, and worse clinical status and prognosis (4 deaths $v$ no deaths at 6 month follow up) than patients with a dominant LF band. In the post-transplant patients both the mean $P P$ interval of the remnant atrium and total power resembled results in the patients with heart failure; in 7 of the 13 post-transplant patients no power was detectable in the LF band: when both HF and LF power were present the results resembled those in the 16 patients in heart failure.
Conclusions-These data suggest that in more advanced stages of congestive heart failure, power spectral analysis of heart rate variability allows identification of a subgroup of patients with higher sympathetic activation and poorer clinical status who are at major risk of adverse events. In the short term after cardiac transplantation the spectral profile of the rhythm variability of the remnant atrium was not improved, suggesting that parasympathetic withdrawal and sympathetic hyperactivity persist, despite the restoration of ventricular function.

(Br Heart f 1994;71:422-430)

Heart failure in both experimental and clinical settings is associated with considerable neurohumoral excitation, resulting in abnormal autonomic control of cardiovascular function. Increased sympathetic activity and plasma concentrations of noradrenaline. ${ }^{12}$ parasympathetic withdrawal, ${ }^{3-5}$ and impaired baroreflex gain ${ }^{6-8}$ have been reported. This excessive neurohumoral activation is involved in progression of heart failure and in prognosis.

Analysis of heart rate variability is regarded a valid technique to assess non-invasively the sympathovagal balance of the heart. Frequency domain analysis of heart rate fluctuations identifies the relative influence of the two neural limbs that regulate heart rhythm. ${ }^{9-11}$ When this technique was used to study patients in congestive heart failure the results did not accord, perhaps because methods and patient selection differed. ${ }^{45}$

Parasympathetic activity assessed by time domain analysis of the variability of the sinus rhythm in the remnant remained subnormal 4-8 weeks after cardiac transplantation despite restoration of normal left ventricular function. ${ }^{12}$ There are no data on frequency domain measurements of recipient sinus rhythm variability. Such analysis might give better discrimination of the role of sympathetic activity in the recovery of autonomic function.

In our present study we tested the hypothesis that power spectrum analysis of heart rate variability in congestive heart failure may identify patients with a more pronounced 
sympathovagal imbalance and who, as a consequence, could be at major risk of the disease worsening and have a poorer prognosis. We also used power spectral estimates of recipient sinus rhythm fluctuations to assess the sympathetic and parasympathetic modulation of the heart after haemodynamic function had been improved by heart transplantation.

\section{Patients and methods}

\section{PATIENTS}

We studied three groups of patients.

Group 1-Thirty patients (mean (SE) age 54(3)) with severe congestive heart failure secondary to ischaemic $(n=19)$ or idiopathic $(n=11)$ cardiomyopathy who were already on the waiting list for cardiac transplantation. The mean (SE) duration of symptoms was 24(4) months. All patients were being treated with diuretics and vasodilators; 18 were receiving digoxin and 11 amiodarone. All were in a stable condition with no change in signs and symptoms within two weeks of the measurement of heart rate variability. None had had an acute myocardial infarction or had undergone cardiac surgery during the previous three months. We excluded patients with more than $10 / \mathrm{min}$ supraventricular and/or ventricular extrasystoles.

Group 2-We studied 20 patients who were referred to the Montescano Medical Centre after orthotopic cardiac transplantation (mean (SE) age 45(4) yr) between January 1991 and December 1991. All heart transplantations were performed at the Policlinico S. Matteo, Pavia by a standard surgical technique. ${ }^{1314}$ During the operation the recipient ventricles and portions of the atria were removed while the great vein-atrial junctions and recipient sinus node remained in situ. Heart transplantation was completed by suturing the donor ventricles and portions of the donor atria to the recipient atrial remnants, which remained normally innervated. Heart rate variability was measured 40(5) days (range 15-68 days) after the operation when there was minimal or no rejection according to cardiac biopsy performed within 5 days of the study. Before heart transplantation eight patients had coronary artery disease and 12 had idiopathic cardiomyopathy: the mean duration of heart failure symptoms was 18(3) months. All 20 transplant recipients were treated with cyclosporin, azathioprine, and prednisone immunosuppression and 15 were also treated with diuretics. None was treated with vasodilators, digitalis, or $\beta$ blockers. We excluded patients in whom hypertension developed (diastolic pressure $>100 \mathrm{~mm} \mathrm{Hg}$ or systolic pressure $>160 \mathrm{~mm} \mathrm{Hg}$ ) and those who had diabetes. Thirteen transplant recipients completed the study: four patients were excluded because of hypertension, an oesophageal recording could not be obtained in two, and in one the remnant atrium showed atrial fibrillation.

In the heart failure and post-transplant groups we measured serum electrolyte concentrations and arterial blood gases and performed renal function studies within 24 hours of the study; no patient had hypoxaemia, hypercapnia, or acidaemia.

Group 3-The control group comprised 15 (mean age 57(3) yr) with ischaemic heart disease with no signs or symptoms of ventricular dysfunction (ejection fraction $>50 \%$, NYHA class 0 or 1) and no ischaemia during effort tests, Holter monitoring, or thallium-201 scintigraphy. Patients with a history of hypertension and diabetes were excluded. None had had myocardial infarction or had undergone coronary angioplasty, or bypass grafting in the preceding 6 months.

All patients gave their informed consent and the study protocol was approved by the local ethics committee.

\section{RECORDINGS}

Studies were carried out in the morning with the subjects in a supine position and fasting. In all groups a standard ECG lead and respiratory signal (via an endonasal thermistor) were recorded and analysed off line. In posttransplant patients the PP interval recordings were obtained from the recipient atrium by an oesophageal ECG lead that transmitted both donor and remnant atrial activity; electrical activities were then separated by digital filtering and averaging techniques (see data processing). After $30 \mathrm{~min}$ of supine rest, which allowed for stabilisation, recordings were performed for at least $30 \mathrm{~min}$, while the patient was breathing spontaneously.

\section{DATA PROCESSING}

The signal processing was performed at the Departments of Biomedical Engineering in the Medical Centre of Montescano (Pavia) and in the Polytechnic University of Milan.

Signal acquisition-All $30 \mathrm{~min}$ recordings were split into segments of at least 512 beats; segments containing artefacts and fast transients were excluded. Final data are the mean of at least three good quality recording segments for each patient. Signals were digitised off line by a 12 bit, analogue to digital converter board, amplitude $\pm 5 \mathrm{~V}$ (Metrabyte Das-8, Texas, USA) at a sampling rate of $300 \mathrm{~Hz}$. Associated RR and PP intervals were measured from the zero-crossing point of the interpolated first derivative of the signal. This increased the time resolution by up to $1 \mathrm{~ms}$. For each RR and PP interval we took a sample of the respiratory signal that corresponded with the $R / P$ wave to obtain the reference value of the respiratory frequency. The beatto-beat series of respiratory values is called a respirogram. ${ }^{15}$ Premature extrasystoles were identified and corrected by linear interpolation with the previous and following beats. Possible artefacts and noise were also excluded. We singled out the activity of the recipient atrium by using a procedure of weighed averaging on a beat-to-beat basis on the oesophageal lead trace (fig 1A) that was synchronised with the maxima of QRS peaks of the donor heart activity previously acquired from the surface ECG (fig 1B). In this way we obtained an averaged QRS complex of donor rhythm (template) with a temporal window of 
Figure 1 (A) Signal from oesophageal lead showing both donor heart (D) and remnant atrium (R) rhythms. Two different and unrelated rhythms are clearly detectable (B) Example of a surface ECG signal of the donor heart (D). (C) Example of remnant atrium electrical activity obtained after separation of donor heart ECG by the averaging procedure reported in the text.

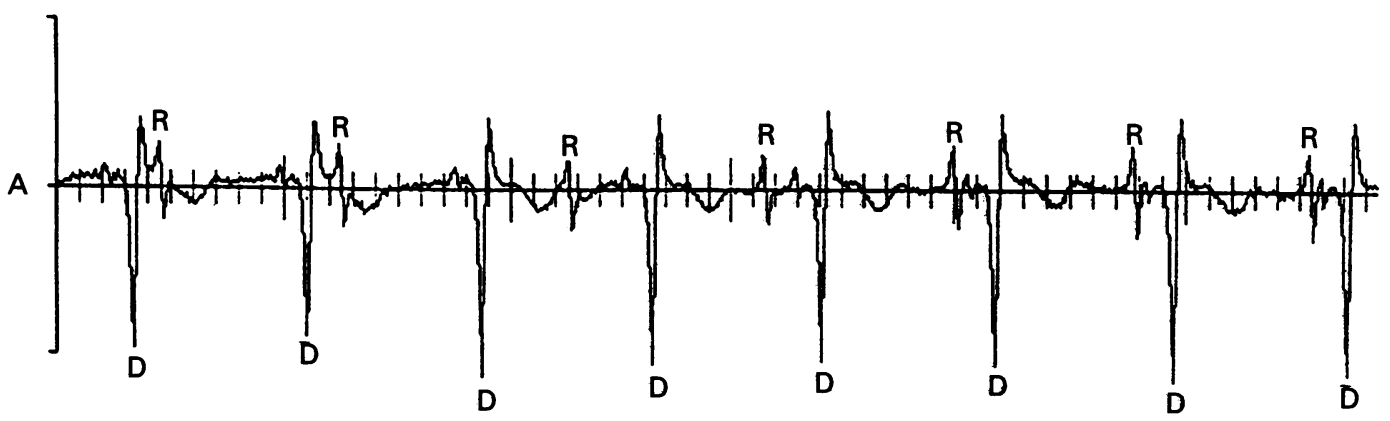

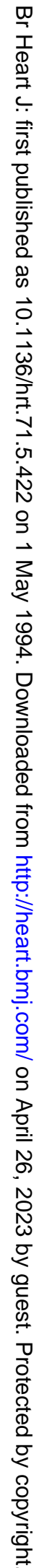

$200 \mathrm{~ms}$ before and $450 \mathrm{~ms}$ after the $R$ peak. We subtracted this template from the original oesophageal signal after synchronisation with donor QRS maxima and using an adaptive gain that depended on the QRS amplitude. ${ }^{16}$ From the resulting signal (fig 1C), which represents the electrical activity of the recipient atrium, and from the donor heart signal, we calculated a time discrete series of successive PP and RR intervals (tachograms, see fig 2).

Signal processing - The time series of the $R R$ and PP intervals were analysed on a personal computer and the power spectral density was calculated according to an autoregressive model estimation. The autoregressive technique calculates the model for the data generation mechanisms by a least squares minimisation of the prediction error. Such a model also allows for the entire spectrum to be divided into single spectral components (one for each degree of freedom of the model itself). The optimum order of autoregressive model identification was chosen by minimisation of the Akaike Information Criteria figure of merit, starting from a minimum of 8 . The reliability of the identification (and hence the fitting of the model to the generated data) was tested by applying the Anderson test (whiteness test) to the prediction error. Records of data that did not fall within $95 \%$ confidence intervals for this test were excluded from the analysis. ${ }^{17}$ For each sequence, the main spectral components were identified automatically and their power and central frequency were computed according to the method proposed by Zetterberg. ${ }^{18}$ The following variables were analysed: $(a)$ average value of the sequence (mean RR or mean PP); (b) total power (total variance of mean $R R$ or $P P$ variability); (c) low frequency power $(0.03-0.15 \mathrm{~Hz})$ in power spectral density, which reflects modulation by both sympathetic and parasympathetic cardiac efferent activity ${ }^{9-11} 19-22 ;$ (d) high frequency power $(0.15-0.45 \mathrm{~Hz})$ in power spectral density, which reflects modulation by parasympathetic activity synchronous with respiration ${ }^{9-11} 192324$; (e) low frequency power/ high frequency power ratio, which reflects the balance between the sympathetic and parasympathetic limbs. ${ }^{11}$ The power spectrum of the respirogram (see above, signal acquisition) was used to detect correctly the high frequency peak on $R R$ and PP signals to establish whether occasional slow respiration rates produced a spurious oscillation in the low frequency band. The very low frequency (VLF) power $(0-0.03 \mathrm{~Hz})$ component was not analysed. This power, though it may contain clinical information, ${ }^{4}$ is erratic when it is measured over a few minutes because it is affected by baseline wandering and other sources of slow frequency noise. VLF components are currently investigated on longer variability series by non-linear modelling of deterministic chaos, in an attempt to evaluate the complex dynamics of long-term regulation 
Figure 2 Beat-to-beat variability signals (tachograms) after hear transplantation. (A) Series of $R R$ intervals of the donor denervated heart, (B) series of PP intervals of the remnant atrium oesophageal ECG, (C) series of respiratory values corresponding with the occurrence of $R$ peak. $A U$, arbitrary units. extracted from the

A (s)

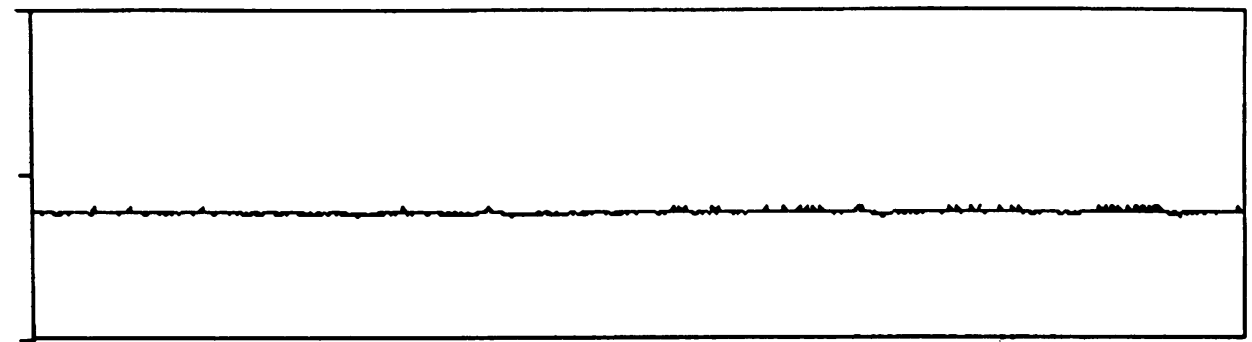

B (s)

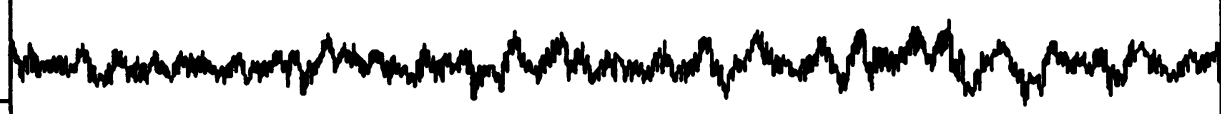

$\mathrm{C}(\mathrm{Au})$

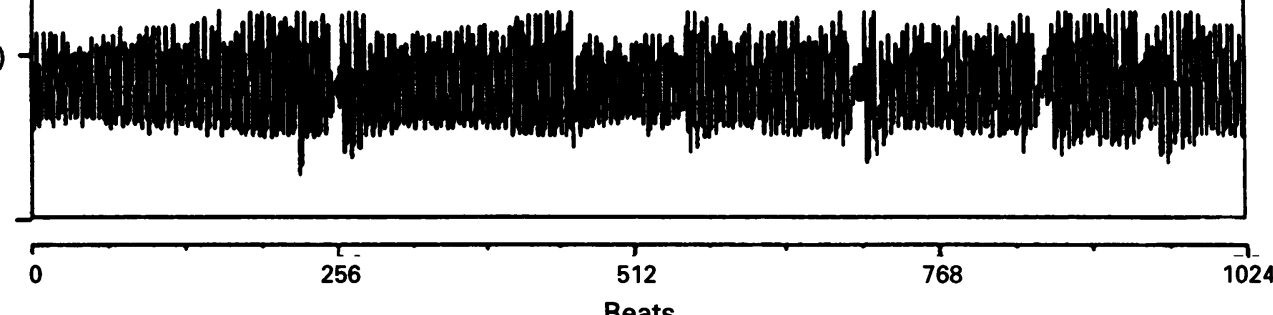

mechanisms that are believed not to be fixed at a certain frequency or frequency band.

Each spectral component is presented in its absolute value $\left(\mathrm{ms}^{2}\right)$ and in normalised units (nu) obtained by dividing the absolute power of the component by the total power minus the VLF component (if present), and multiplying by 100 . Only components making up $>5 \%$ of the total power were considered for the study.

\section{Measurement of plasma noradrenaline}

Noradrenaline was assayed in $6 \mathrm{ml}$ samples of blood drawn from the forearm vein and col-

Table 1 Patients' characteristics (mean (SEM))

\begin{tabular}{|c|c|c|c|}
\hline \multirow[b]{2}{*}{ Characteristic } & \multirow{2}{*}{$\begin{array}{l}C H F \\
(n=30)\end{array}$} & \multicolumn{2}{|l|}{$C T(n=13)$} \\
\hline & & Pre & Post \\
\hline $\begin{array}{l}\text { Age (y) } \\
\text { NYHA class (\%) }\end{array}$ & $54(3)$ & \multicolumn{2}{|c|}{$45(4)$} \\
\hline $\begin{array}{l}\text { NYHA class }(\%) \\
\text { III }\end{array}$ & $22(73)$ & $5(38)$ & $0(0)$ \\
\hline IV & $8(26)$ & $8(62)$ & $0(0)$ \\
\hline $\mathrm{EF}(\%)$ & $19 \cdot 5(1 \cdot 1)$ & $17.9(0.9)$ & $55 \cdot 4(2 \cdot 5)$ \\
\hline $\mathrm{CI}\left(\mathrm{l} / \mathrm{min} / \mathrm{m}^{2}\right)$ & $2.04(0.1)$ & $2.06(0.2)$ & $3.35(0.2)$ \\
\hline $\mathrm{PCP}(\mathrm{mm} \mathrm{Hg})$ & $21 \cdot 1(1 \cdot 8)$ & $22.9(3.4)$ & $10.4(1.9)$ \\
\hline $\mathrm{RAP}(\mathrm{mm} \mathrm{Hg})$ & $6.8(1.5)$ & $9 \cdot 5(1 \cdot 2)$ & $2 \cdot 0(0 \cdot 3)$ \\
\hline PAR (mm Hg/l/min) & $2 \cdot 6(0 \cdot 7)$ & $2 \cdot 7(0 \cdot 7)$ & $1 \cdot 1(0 \cdot 2)$ \\
\hline Symptoms (mnth) & $24(4)$ & $18(3)$ & \\
\hline $\mathrm{Na}+(\mathrm{mEq} / \mathrm{dl})$ & 137 (1) & $136(2)$ & $139(0 \cdot 7)$ \\
\hline $\mathrm{Po}_{2}(\mathrm{~mm} \mathrm{Hg})$ & $77(2 \cdot 5)$ & N/A & $87(2 \cdot 8)$ \\
\hline $\mathrm{PCO}_{2}(\mathrm{~mm} \mathrm{Hg})$ & $36(1.5)$ & N/A & $34(1.0)$ \\
\hline Days from CT & - & - & $40(5)$ \\
\hline Cyclosporin (ng/dl) & - & - & $267(21)$ \\
\hline \multicolumn{4}{|l|}{ Medication (\%) } \\
\hline Diuretic & $30(100)$ & $13(100)$ & $11(85)$ \\
\hline Digitalis & $18(60)$ & $7(54)$ & $0(0)$ \\
\hline ACE inhibitors & $27(90)$ & $13(100)$ & $0(0)$ \\
\hline Nitrates & $12(40)$ & $6(46)$ & $0(0)$ \\
\hline Amiodarone & $11(37)$ & $4(31)$ & $0(0)$ \\
\hline Immunosuppression & - & - & $13(100)$ \\
\hline
\end{tabular}

N/A, not available; CHF, congestive heart failure; CT, cardiac transplantation; EF, ejection fraction; CI, cardiac index; PCP, pulmonary capillary pressure; RAP, right atrial pressure; PAR pulmonary arteriolar resistance; $\mathrm{PO}_{2}$, partial pressure of oxygen in blood; $\mathrm{PCO}_{2}$, partial pressure of carbon dioxide in blood. lected into chilled tubes containing $1 \mathrm{mg} / \mathrm{ml}$ EDTA for immediate storage at $-70^{\circ} \mathrm{C}$. Plasma noradrenaline was measured by high performance liquid chromatography with electrochemical detection as described elsewhere. ${ }^{25}$ In our laboratory the mean value of normal subjects is $275(34) \mathrm{pg} / \mathrm{ml}$.

\section{STATISTICAL ANALYSIS}

All results are reported as mean (SEM). Groups were compared by a general linear model one way analysis of variance and variables were compared by linear regression analysis. Before statistical analysis we log transformed the power spectral variables to produce distributions that were nearly normal. Differences with a $p$ value of $<0.05$ were regarded as statistically significant.

\section{Results}

Table 1 summarises the general characteristics of the patients with heart failure and the post-transplant patients. There was no difference in mean age between the two groups though the post-transplant recipients tended to be younger than those with heart failure.

The patients with congestive heart failure and the transplant patients (before the operation), had similar ejection fractions, haemodynamic variables, and NYHA class distribution.

\section{HEART PERIOD VARIABILITY}

Table 2 lists the indices of power spectrum estimate.

Group 1-As expected, patients with heart failure had a reduced mean $R R$ interval and total power than the control group $(803(24) v$ 
Table 2 Indices of heart rate variability (mean (SEM))

\begin{tabular}{|c|c|c|c|c|c|c|c|}
\hline & $\begin{array}{l}\text { Mean } R R \\
\text { (ms) }\end{array}$ & $\begin{array}{l}\text { Total Power } \\
\left(m s^{2}\right)\end{array}$ & $\begin{array}{l}L F \\
\left(m s^{2}\right)\end{array}$ & $\begin{array}{l}L F \\
(n u)\end{array}$ & $\begin{array}{l}H F \\
\left(m s^{2}\right)\end{array}$ & $\begin{array}{l}H F \\
(n u)\end{array}$ & $\begin{array}{l}L F / H F \\
\text { (ratio nu) }\end{array}$ \\
\hline \multicolumn{8}{|l|}{ CHF: } \\
\hline $\begin{array}{l}\text { Total group }(n=30) \\
\text { With LF }(n=16) \\
\text { Without LF }(n=14)\end{array}$ & $\begin{array}{l}803(24)^{\star} \\
864(36) \S \\
745(25) \oint\end{array}$ & $\begin{array}{l}496(121) \dagger \\
902(202) \ddagger \\
118(16) \ddagger\end{array}$ & $203(55)$ & $67(6)^{\star}$ & $\begin{array}{l}78(23) \\
82(28)\end{array}$ & $\begin{array}{l}26(5)^{*} \\
69(4)\end{array}$ & $3.31(0 \cdot 8)^{\star}$ \\
\hline \multicolumn{8}{|l|}{ CT (rec): } \\
\hline $\begin{array}{l}\text { Total group }(n=13) \\
\text { With LF }(n=6) \\
\text { Without LF }(n=7)\end{array}$ & $\begin{array}{l}809(44) \star \int \\
816(58) \S \\
803(70) \oint\end{array}$ & $\begin{array}{l}324(91) \dagger \ddagger \\
527(33) \neq £ \\
150(46) \neq \S\end{array}$ & $209(57)$ & $72(8)^{\star}$ & $\begin{array}{l}53(29) \\
72(32)\end{array}$ & $\begin{array}{l}14(3)^{\star} \\
62(9)\end{array}$ & $5 \cdot 21(1 \cdot 5)^{\star}$ \\
\hline \multicolumn{8}{|l|}{ CT (don): } \\
\hline $\begin{array}{l}\text { Total group }(n=13) \\
\text { With LF }(n=5)\end{array}$ & $\begin{array}{l}755(27)\} \\
772(28)\end{array}$ & $\begin{array}{l}12(3) \ddagger \\
12(8)\end{array}$ & $1.5(1)$ & $24(3)$ & $5 \cdot 8(2)$ & $63(4)$ & $0.46(1.6)$ \\
\hline Without LF $(n=8)$ & 744 (59) & $11(6)$ & & & $4 \cdot 4(1)$ & $57(8)$ & - \\
\hline Controls $(n=15)$ & $921(37)$ & $1821(325)$ & $354(87)$ & $49(3)$ & $223(55)$ & $38(3)$ & $1.6(0.6)$ \\
\hline
\end{tabular}

CHF, chronic heart failure; CT (rec), recipient atrium rhythm; CT (don), donor heart rhythm; LF, low frequency power; HF, high frequency power

$\star \mathrm{p}<0.05 v$ controls; $\mathrm{f} \mathrm{p}<0.002 v$ controls; $\neq \mathrm{p}<0.005 ; \mathrm{\rho}<<0.05$.

921(37) $\mathrm{ms}(\mathrm{p}<0.05)$ and 496(121) v 1821(325) $\mathrm{ms}^{2},(\mathrm{p}<0.002)$ respectively). Spectral analysis did not show any LF component (specifically any discrete peak in the $0.03-0.15 \mathrm{~Hz}$ band) in 14 of the 30 patients studied, whereas in the remaining subjects

Undetectable LF

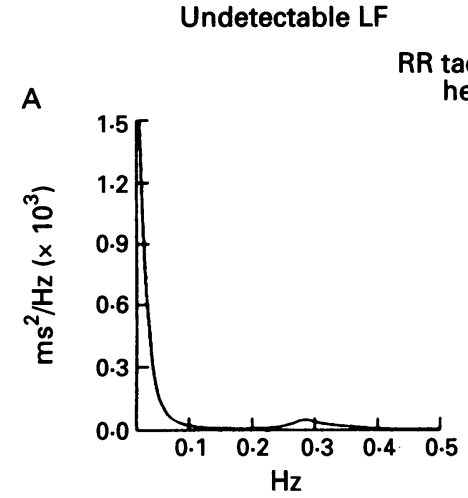

RR tachogram PSD heart failure
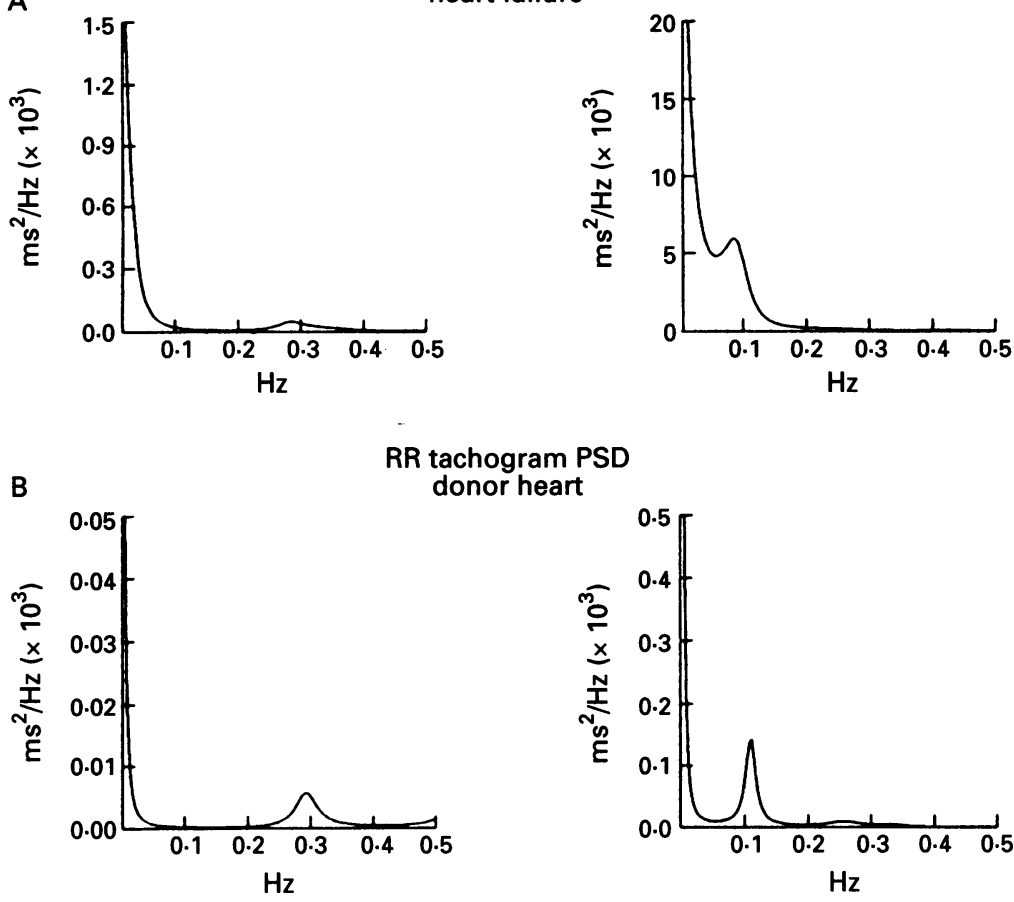

tachogram PSD
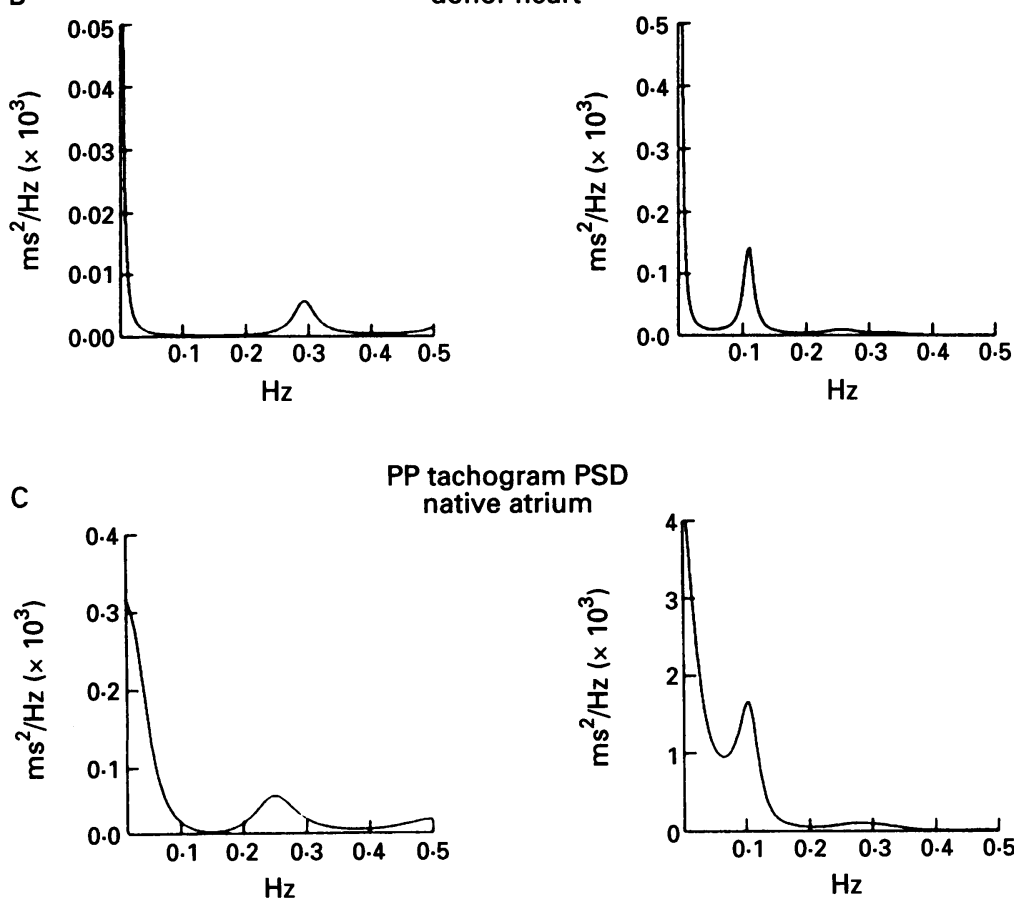

P tachogram PSD

native atrium

Figure 3 Examples of decomposition of the entire spectrum into the single spectral components from a patient with heart failure $(A), a$ donor heart $(B)$, and a native atrium (C). In all the groups on the left the low frequency power was undetectable and the small amount of total variability was concentrated in the high frequency band; the prevalence of low frequency power is shown on the right hand side. PSD, power spectral density. the LF component predominated over the $\mathrm{HF}$ component (LF $=203(55) \mathrm{ms}^{2}, \mathrm{HF}=$ 78(23) $\mathrm{ms}^{2}$ ) fig $3 \mathrm{~A}$ ). The finding was the same when the LF and HF components were expressed as normalised units: both LF and the LF/HF ratio were significantly higher and HF was significantly lower in patients with heart failure than in the controls (LF 67(6) $v$ 49(3) nu, p < 0.05; HF 26(5) v 38(3) nu, p < $0.05 ; \mathrm{LF} / \mathrm{HF}$ ratio $3.31(0.8) v 1.6(0.6), \mathrm{p}<$ 0.05). Mean RR and total power were lower in patients without a detectable LF component than in those with an LF component (RR 745(25) $v$ 864(36) ms, p < 0.05; TP 118(16) $v$ 902(202) $\left.\mathrm{ms}^{2}, \mathrm{p}<0.005\right)$. Moreover ventricular function (ejection fraction $17 \cdot 7(1) v 21.4(1) \%, \mathrm{p}<0.05)$ and functional class ( 8 class IV plus 6 class III $v 16$ class III) were worse in those patients without detectable LF than in those with a detectable LF component.

Plasma noradrenaline was measured in the last 14 patients examined (mean 461(60) $\mathrm{pg} / \mathrm{ml}$ ). Concentrations were significantly higher in patients with undetectable LF than in those with detectable LF (635(75) $v$ $329(54) \mathrm{pg} / \mathrm{ml}, \mathrm{p}<0.05)$

Post-transplant group-We analysed the heart rate variability of the $R R$ interval sequences of the donor heart and the PP interval sequences of the recipient atrium, which is normally innervated and can reflect the changes in the sympathovagal activity of the heart after the restoration of the cardiac function. The mean $R R$ interval of the donor heart was $755(27) \mathrm{ms}$; there was little fluctuation around the mean and the total power was 12(3) $\mathrm{ms}^{2}$. In all donor recordings a high frequency component was evident, whereas no power in the low frequency band was detectable in eight of the 13 patients. Five had a well defined low frequency peak though it was of a very low amplitude (1.5(1) $\mathrm{ms}^{2}$, 24(3) nu, 0.09(0.02) Hz) (fig 3B). Compared with the donor rhythm, the recipient atrium showed a significantly different mean PP interval $(809(44) \mathrm{ms}, \mathrm{p}<0.05)$, and a greater total power $\left(324(91) \mathrm{ms}^{2}, \mathrm{p}<0.005\right)$. Spectral components of PP variability were detected at the same frequency bands as the donor heart fluctuations (LF $0.091(0.01) v$ $0.088(0.02) \mathrm{Hz}$, NS; HF $0.30(0.03) v$ $0.30(0.02) \mathrm{Hz}, \mathrm{NS})$. The LF component was 
Figure 4 Relation between total power $\left(\mathrm{ms}^{2}\right)$ and interval since cardiac transplantation (CT).

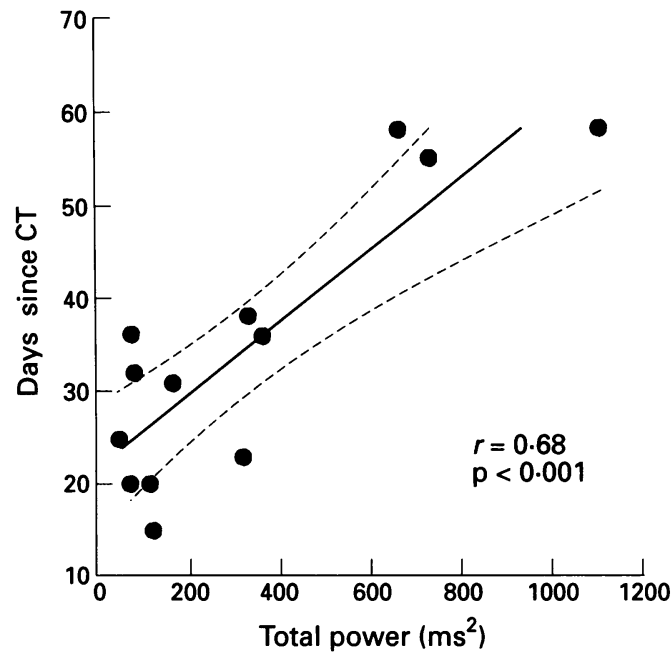

still not detectable in seven of the 13 patients (example fig 3C). The LF component (when present), and HF component were both of significantly greater amplitude than the donor rhythm components (LF 209(57) $v$ 1.5(1) $\mathrm{ms}^{2}$; HF 63(21) v 5.1(1) $\left.\mathrm{ms}^{2}\right)$. Like the patients with heart failure, post-transplant patients with a detectable LF component had a larger total power than those without LF (527(33) $\left.v 150(46) \mathrm{ms}^{2}, \mathrm{p}<0.05\right)$; also the interval between operation and assessment of heart period variability was significantly longer in those with LF (respectively 51(5) $v$ 29(6) days, $\mathrm{p}<0.05$ ).

COMPARISON BETWEEN PATIENTS WITH HEART FAILURE AND POST-TRANSPLANT PATIENTS

There were no significant differences between
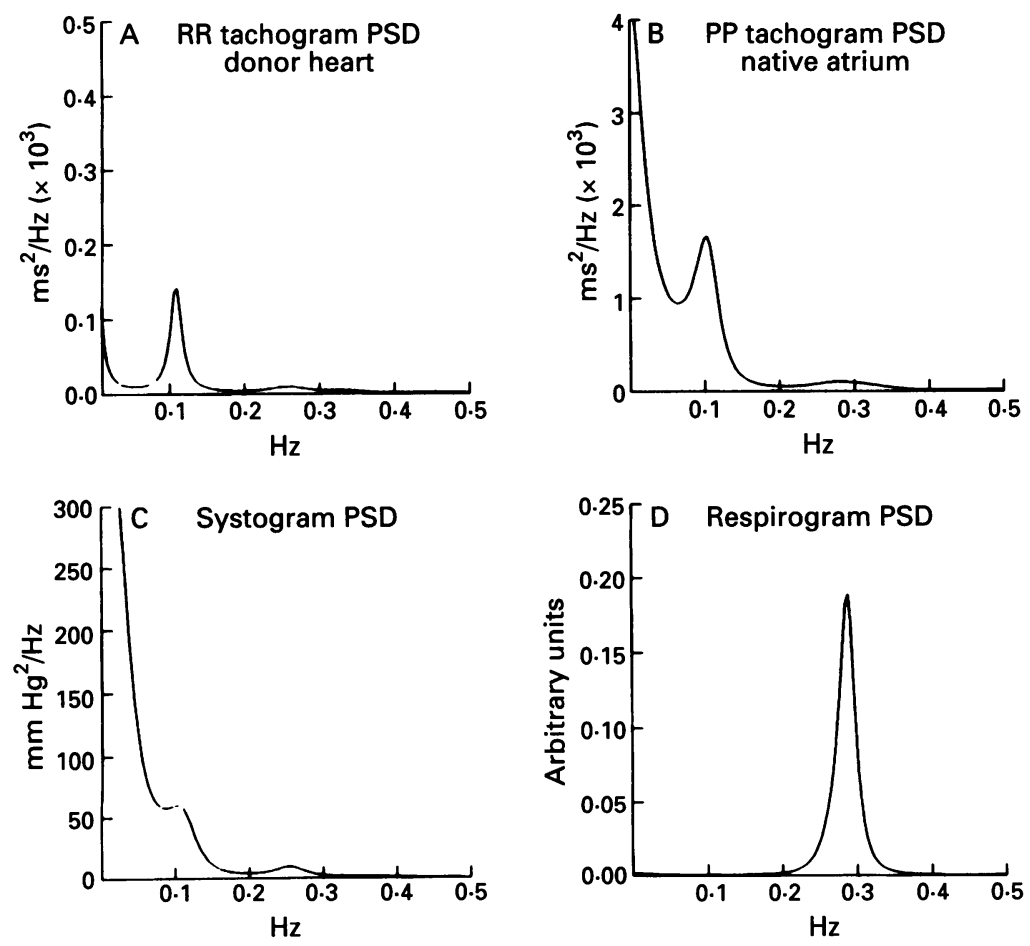

Figure 5 Examples of spectral decomposition of donor heart $(A)$ and native atrium $(B)$ tachograms, systogram (systolic arterial pressure time series) (C) and respirogram (D) in the same recording segment. In panel $A$ there is a defined peak in the low frequency band, synchronous (coherence $=K 2>0.5$ ) with the systogram and tachogram of the native atrium, suggesting a possible influence of systolic pressure fluctuations on donor heart rhythm variability. the spectral indices of PP variability of the post-transplant remnant atrium and the $R R$ variability of patients with heart failure. The two groups showed a similar mean PP and RR interval (809(44) $v$ 803(24) $\mathrm{ms}, \mathrm{p}=0.76$ ) and no significant difference in total power (324(91) $v$ 496(121) $\mathrm{ms}^{2}, \mathrm{p}=0.49$ ). In addition the percentages of patients with an undetectable LF component ( $54 \% \quad v \quad 47 \%)$ and both LF (when present), and HF powers were not significantly different in the two groups.

CORRELATION WITH CLINICAL VARIABLES

In both groups (heart failure and post-transplant) there was no significant correlation between the duration of heart failure symptoms and the mean PP or RR interval and total power. Blood sodium concentration and blood gas partial pressures were not related to the indices of heart period variability. In posttransplant patients plasma cyclosporin concentrations were unrelated to the rhythm variability of the recipient atrium $(r=0.40, p=$ $0 \cdot 17$ ) whereas the total power of the mean PP interval was significantly related to the interval since heart transplantation $(r=0.68, p<$ $0 \cdot 01$ ) (fig 4).

\section{Discussion}

Our data showed that in the more advanced stages of heart failure, heart rate variability was so reduced that neural modulation of cardiac rate seemed almost lost. Power spectral analysis of heart rate variability may allow identification of a subgroup of patients-with undetectable power in the low frequency band-who show increased sympathetic activation as assessed by plasma noradrenaline blood concentrations, more severe clinical status, and a worse prognosis. The spectral profile of the variability of the recipient sinus node soon after cardiac transplantation showed that sympathetic overactivity and parasympathetic withdrawal persisted despite restoration of ventricular function.

\section{HEART PERIOD VARIABILITY IN CONGESTIVE} HEART FAILURE

Like others we found that heart period variability was reduced in patients with congestive heart failure. ${ }^{452627} \mathrm{We}$ identified two different spectral patterns. The first was characterised by a predominant LF component and a reduced HF component, suggesting sympathetic predominance and parasympathetic withdrawal. In the second we found a major reduction in total power, an undetectable LF component and a low amplitude HF peak. Patients with undetectable LF were more severely affected, with depressed left ventricular function and a higher degree of sympathoexcitation, reflected by the higher plasma noradrenaline concentrations. The apparent paradox of more pronounced sympathetic hyperactivity associated with an undetectable LF component (considered by some to be a marker of sympathetic activity 9111922 is explained by the concept that in the more severe stages of the disease the neurohormonal excitation reduces reflex 
modulation of heart rate to a such extent that above $0.03 \mathrm{~Hz}$, only small fluctuations that are synchronous with breathing activity are detectable. ${ }^{24} 28$ Interestingly the progressive reduction in the LF power that is seen during exercise-induced sympathetic hyperactivation seems to confirm that this part of the spectrum is markedly affected by overstimulation of the sympathetic system. ${ }^{29}$ Hence, in our population, patients with undetectable LF and much reduced total power may be regarded as the far end of a range of sympathoexcitation which can be assessed by heart rate variability. Recent data showing a close and negative correlation between the amount of heart rate variability and plasma noradrenaline concentrations or muscle sympathetic activity are consistent with this idea. ${ }^{27}$ On the other hand we cannot exclude the possibility that abnormalities or "saturation" of the response of the sinus node to changes in efferent traffic can conceal the sympathetic overactivity on heart rate fluctuations.

Our data accord with studies by Saul et al ${ }^{4}$ even though they used a different processing method; they reported no power component between 0.04 and $0.15 \mathrm{~Hz}$ and a small but discernible peak in the HF band. Saul et al detected a consistent power in the VLF band (below $0.04 \mathrm{~Hz}$ ) but this was less effective in distinguishing between heart failure patients and controls than distribution of the power above $0.04 \mathrm{~Hz}$. Though the power in the VLF band may be of clinical relevance (despite the absence of experimental data), we focused our attention on the two bands (LF and HF) that at experimental and clinical levels have been more extensively related to the sympathovagal activity that modulates the heart rhythm..$^{9-1122}$

It has been suggested that parasympathetic activity is inversely related and that sympathetic activity and noradrenaline concentrations are directly related to the severity of heart failure and prognosis. ${ }^{13} 3031$ Though we studied only a small number of patients, within a follow up of six months there were four deaths (two of them due to arrhythmia and two preceded by symptoms of worsening pump failure) in the patients with undetectable LF and no deaths in the group in which the LF component predominated over the HF component. These findings raise the possibility that in patients with heart failure the extent of autonomic abnormalities gives information on the prognosis, just as reduced heart rate variability and depressed baroreflex sensitivity do after myocardial infarction. ${ }^{32} 33$ Specifically a pattern of low total power and an undetectable LF component may be useful in identifying heart failure patients with a more pronounced sympathoexcitation.

\section{HEART PERIOD VARIABILITY AFTER HEART TRANSPLANTATION}

\section{Denervated heart}

As in other studies ${ }^{34-36}$ the heart rate variability of the denervated heart was markedly reduced by the interruption of the sympathetic and parasympathetic fibres. There is controversy over whether any power spectral components are recognisable after spectral decomposition. In all patients we detected a high frequency peak that was synchronous with respiration. In the denervated heart the high frequency component was interpreted as being caused by an intrinsic mechanism (mechanically induced) of the heart muscle independent of neural regulation. ${ }^{24}$ In a few patients we also observed a well defined peak in the low frequency band that cannot simply be due to sympathetic or baroreflex activity (as it is in the intact heart). This observation is consistent with previous reports, ${ }^{3536}$ and it is not accounted for by the results presented in this paper. However, when we examined our preliminary data on polyparametric spectral analysis of different signals in post-transplant patients (donor heart rate, recipient atrium rate, respiratory signal, and systolic blood pressure), we found that the low frequency peaks of the donor heart and remnant atrium and systolic blood pressure variability, if present, were all in the same frequency band $(0 \cdot 08-0 \cdot 1 \mathrm{~Hz})$ and significantly coherent $(\mathrm{K} 2>0.5)$, occurring at a frequency not related to breathing activity (fig 5). If confirmed, these data indicate a possible influence of systolic pressure fluctuations on the variability of the donor heart rhythm.

\section{Recipient remnant atrium}

During heart transplantation a portion of the recipient atrium, including the sinus node, is left in situ and remains normally innervated. Thus the analysis of the sinus node variability of the remnant atrium gives an opportunity of studying the sympathovagal influences on the heart after normal haemodynamic function is restored. In heart failure patients the time domain indices of heart rate variability remained subnormal after cardiac transplantation. ${ }^{12}$ We attempted to distinguish between the contributions of vagal and sympathetic activity by using frequency domain measurements. In our study the total spectral variability of the PP interval was significantly larger than the donor rhythm variability, confirming that there is neural modulation of the recipient sinus node. We also found in these sequences that breathing activity regulates the heart rate fluctuations in the high frequency band and that the low frequency component is detectable only in subjects with larger variability. Our comparison of power spectrum findings in post-transplant and heart failure patients showed that 4-6 weeks after transplantation all the spectral indices of heart period variability of the innervated recipient atrium were still impaired. In our population total power was reduced in all patients and the low frequency component was not detectable in seven out of 13 patients. Table 2 shows that neither the high frequency nor low frequency components, when present, had a significantly different power compared with the heart failure group, thus suggesting that sympathetic overactivity and parasympathetic withdrawal had not returned to normal. These observations suggest that nerve traffic to the heart is not restored by haemodynamic 
improvement soon after heart transplantation, and tends to normalise later. This timedependent resumption was reported by oth$\operatorname{ers}^{712}$ and there is evidence for it in our study in the significant correlation between total power and the interval since heart transplantation. These observations of a delayed resumption of variability of the remnant sinus node despite normalisation in left ventricular function indicate that remnant atrium variability is unlikely to be a reliable marker of sympathovagal balance after heart transplantation. Nevertheless, despite removal of its normal blood supply the recipient sinus node usually remained viable and responded appropriately to physiological stimuli. ${ }^{14} 37$

MECHANISMS OF SYMPATHETIC OVERACTIVITY AFTER SHORT-TERM HEART TRANSPLANTATION Though restoration of the balance of sympathovagal influence on the heart after transplantation is time dependent, our data showed that 4-6 weeks after the operation both parasympathetic withdrawal and sympathetic overactivity persisted. Evidence of sympathetic overactivity was reported by Mohanty et al $^{38}$ who found that forearm vasoconstriction and plasma noradrenaline responses to the application of lower body negative pressure were also impaired after orthotopic heart transplantation despite the normalisation of resting noradrenaline concentrations. Moreover, muscle sympathetic nerve overactivity was detected in post-transplant patients when plasma noradrenaline concentrations were much lower than in congestive heart failure but still in the upper limit of the normal range. ${ }^{39}$ These findings suggest only a weak correlation between noradrenaline concentrations and sympathetic nerve traffic in post-transplant patients.

The sympathovagal imbalance we found 4-6 weeks after cardiac transplantation may be related to a delayed recovery though other factors contributing to sympathetic overactivity itself cannot be excluded. Among these factors is cardiac surgery which was shown to increase sympathetic outflow to the heart and increase its rate. ${ }^{40}$ Several features of cardiac surgery may be involved. These include the ischaemia time of the donor heart, the anaemia that follows heart transplantation, and manipulation of the pericardium, which in the intact heart regulates sympathetic tone through prostaglandin secretion..$^{41}$ In addition ventricular deafferentation of the donor ventricles may impair the tonic inhibitory influence on the sympathetic outflow that originates from sensory receptors in the cardiopulmonary region. ${ }^{38}$ Cyclosporin treatment too may be involved in sympathetic activation. ${ }^{39}$ Though the influence of cyclosporin cannot be excluded in our study, it seems unlikely, because patients with hypertension were excluded and no relation was found between the blood concentration of cyclosporin and the total heart rate variability. Moreover normotensive patients with kidney transplants treated with similar doses of immunosuppressant therapy did not show any signs of sympathetic cardiac overactivity. ${ }^{38}$ Normal right atrial pressure in our patients (table 1) seems to exclude the possibility of volume overload that could have induced mechanical stretch of the remnant atrium.

\section{POTENTIAL LIMITATIONS}

A possible limitation of our study is that we compared different groups of patients before and after heart transplantation. However, as table 1 shows, the haemodynamic and clinical states of transplant patients before operation resembled the heart failure group. Ventricular function was impaired and the NYHA functional class, indicated a similar imbalance in the autonomic nervous system in all patients. Furthermore we excluded post-transplant patients in whom hypertension developed because this affects the restoration of sympathovagal balance..$^{72}$

Pharmacological agents are among the factors that might have influenced our data. Post-transplant patients were treated mainly with diuretics and none was treated with $\beta$ blockers or calcium antagonists. So this group of patients was influenced solely by immunosuppressive therapy. In the heart failure group a pharmacological influence on sympathovagal balance cannot be excluded, particularly in those patients treated with angiotensin converting enzyme inhibitors or digoxin..$^{42}{ }^{43}$ None the less, the clinical state of our patients would only allow changes or withdrawal of drug therapy at the expense of losing the "steady condition".

In conclusion, in our study, which because of its limited size should be regarded as a pilot study, power spectrum analysis of heart rate variability seemed to be a valid technique to identify non-invasively those patients with severe heart failure who show more pronounced sympathetic activation. If neural derangement is involved in the progression and worsening of heart failure, this subgroup of patients may be at higher risk of adverse events: our limited follow-up data are consistent with this suggestion. In the short-term after heart transplantation the spectral profile of heart rate variability does not seem to improve, suggesting the persistence not only of parasympathetic withdrawal but also of sympathetic hyperactivity. Continuing follow up of such patients will probably clarify the natural course of the recovery and whether a full recovery can be attained.

We thank Cristina Pastorelli, Roberto Maestri, and Antonio Di Cesare for their help throughout the study and Prof Giuseppe Specchia and Prof Peter Schwartz, University of Pavia, for reviewing the paper and for helpful criticism.

1 Cohn JN, Levine TB, Olivari MT. Plasma norepinephrine as a guide to prognosis in patients with chronic congestive heart failure. $N$ Engl F Med 1984;311:819-23.

2 Leimbach WN Jr, Walin BG, Victor RG, Aylward PE, Sundlof G, Mark AL. Direct evidence from intraneura recordings for increased central sympathetic outflow in patients with heart failure. Circulation 1986;5:913-9.

3 Eckberg DL, Drabinsky M, Braunwald E. Defective cardiac parasympathetic control in patients with heart disdiac parasympathetic control in patients

4 Saul JP, Aray Y, Berger RD, Lilly LS, Colucci WS, Cohen RJ. Assessment of autonomic regulation in chronic conRJ. Assessment of autonomic regulation in chronic con-
gestive heart failure by heart rate spectral analysis. $A m \mathcal{F}$
Cardiol 1988;61:1292-9.

5 Binkley PF, Nunziata E, Haas GJ, Nelson SD, Cody RJ. 
Parasympathetic withdrawal is an integral component of autonomic imbalance in congestive heart failure: demonstration in human subjects and verification in a paced canine model. 7 Am Coll Cardiol 1991;18:464-72.

6 Mohanty PK, Arrowood JA, Ellenbogen KA, Thames MD. Neurohumoral and hemodynamic effects of lower body negative pressure in patients with congestive heart body negative pressure in patients with

7 Ellenbogen KA, Mohanty PK, Szentpetery S, Thames $M D$. Arterial baroreflex abnormalities in heart failure: $\mathrm{MD}$. Arterial baroreflex abnormalities in heart failure: reversal after orthotopic

8 Ferguson DW, Berg WJ, Roach PJ, Oren RM, Mark AL. Effects of heart failure on baroreflex control of symp thetic neural activity. Am $\mathcal{F}$ Cardiol 1992;69:523-31.

9 Akselrod S, Gordon D, Ubel FA, Shannon DC, Barger AC, Cohen RJ. Power spectrum analysis of heart rate fluctuations. A quantitative probe of beat-to-beat cardiovascular control. Science 1981;213:220-2.

10 Pomeranz B, Macaulay RJB, Caudill MD, Kutz I, Adam $\mathrm{D}$, Gordon D, et al. Assessment of autonomic function in humans by heart rate spectral analysis. Am $f$ Physiol 1985;248:H151-3.

11 Pagani M, Lombardi F, Guzzetti S, Rimoldi O, Furlan R, Pizzinelli $P$, et al. Power spectral analysis of heart rate and arterial pressure variabilities as a marker of sympatho-vagal interaction in man and conscious dog. Circ Res 1986;59:178-93.

12 Smith ML, Ellenbogen KA, Eckberg DL, Sheehan HM, Thames M. Subnormal Parasympathetic activity after

13 Lower RR, Stofer RC, Shumway NE. Homovital transplantation of the heart. $\mathcal{F}$ Thorac Cardiovasc Surg $1961 ; 41: 196-205$.

14 Stinson EB, Schroder JS, Griepp RB, Shumway NE, Dong E Jr. Observation on the behaviour of recipient atria after cardiac transplantation in man. Am $\mathcal{F}$ Cardiol 1972;30: 615-22.

15 Cerutti S, Alberti M, Baselli G, Rimoldi O, Malliani A, Merri $M$ et al. Automatic assessment of the interaction between respiration and heart rate variability signal. Med Progr Technol 1988;14:7-19.

16 Cerutti S, Baselli G, Civardi S, Ferrazzi E, Pardi G, Marconi AM, et al. Variability analysis of fetal heart rate signals obtained from abdominal ECG recordings. signals obtained from abdominat Med 1986;14:445-52.

17 Baselli G, Cerutti S, Civardi S, Lombardi F, Malliani A Merri $M$, et al. Heart rate variability signal processing: a quantitative approach as an aid to diagnosis in cardio-
vascular pathologies. Int $f$ Bio-Med Computing 1987; vascular patt

18 Zetterberg LH. Estimation of parameters for a linear difference equation with application to ECG analysis. Math Biosci 1978;5:227-75.

19 Akselrod S, Gordon D, Madwed JB, Snidman NC, Shannon DC, Cohen RJ. Hemodynamic regulation Investigation by spectral analysis. Am $\mathcal{F}$ Physiol 1985; 294:H867-75.

20 Appel ML, Berger RD, Saul JP, Smith JM, Cohen RJ. Beat to beat variability in cardiovascular variables: noise or music? $\mathcal{F}$ Am Coll Cardiol 1989;14:1139-48.

21 Bigger JT Jr., Fleiss JL, Steinman RC, Rolnizky LM, Kleiger RE, Rottman JN. Frequency domain measure of heart period variability and mortality after myocardial infarction. Circulation 1992;85:164-71.

22 Rimoldi O, Pierini S, Ferrari A, Cerutti S, Pagani M Malliani A. Analysis of short-term oscillations of R-R Malliani A. Analysis of short-term oscillations of $\mathrm{R}-\mathrm{R}$
and arterial pressure in conscious dogs. Am $\mathcal{f}$ Physiol and arterial pressur.

23 Fouad FM, Tarazi RC, Ferrario CM, Fighaly S, Alicandri C. Assessment of parasympathetic control of heart rate by a non-invasive method. Am F Physiol 1984;246: H838-42.

24 Bernardi L, Keller F, Sanders M, Reddy PS, Griffith B,
Meno F, et al. Respiratory sinus arrhythmia in the denervated human heart. $\mathcal{F}$ Appl Physiol 1989;67:1447-55.

25 Ceconi C, Condorelli E, Quinzanini M, Rodelli A, Ferrar $R$, Harris $P$. Noradrenaline, atrial natriuretic peptide, bombesin, and neurotensin in myocardium and blood of rats in congestive cardiac failure. Cardiovasc Res 1989, 23:674-83.

26 Casolo G, Balli E, Taddei T, Amuhasi J, Gori C. Decreased spontaneous heart rate variability in congesDecreased spontaneous heart rate variability in
tive heart failure. Am $₹$ Cardiol $1989 ; 64: 1162-7$.

27 Kienzle MG, Ferguson DW, Birkett CL, Myers GA, Ber WJ, Mariano DJ. Clinical, Hemodynamic and Sympathetic Neural correlates of heart rate variability in conthetic Neural correlates of heart rate variability in
gestive heart failure. Am $\mathcal{f}$ Cardiol 1992;69:761-7.

28 Hashimoto K, Tanaka S, Hirata M, Chiba S. Responses of the sino-atrial node to change in pressure in the sinu node artery. Circ Res 1967;21:297-304.

29 Perini R, Orizio C, Baselli G, Cerutti S, Veicsteinas A The influence of exercise intensity on the power spectrum of heart rate variability. Eur $\mathcal{f}$ Appl Physiol 1990 61:143-8.

30 Hinkle LE, Carver ST, Plakum A. Slow heart rates and increased risk of cardiac death in middle-aged men. Arch Intern Med 1972;129:732-50.

31 Rector TS, Olivari MT, Levine TB, Francis GS, Cohn JN. Predicting survival for an individual with congestive heart failure using the plasma norepinephrine concentration. Am Heart $\mathcal{1}$ 1987;114:148-52.

32 Bigger JT Jr, Fleiss J, Steinman RC, Rolnitzky LM Kleiger RE, Rottman JN. Frequency domain measures of heart period variability and mortality after myocardial of heart period variability and mortality

33 La Rovere MT, Specchia G, Mortara A, Schwartz PJ. Baroreflex sensitivity, clinical correlates and cardiovascular mortality among patients with a first myocardia infarction. Circulation 1988;78:816-24.

34 Sands KEF, Appel ML, Lilly LS, Schoen FJ, Mudge GH Cohen RJ. Power spectrum analysis of heart rate variability in human cardiac transplant recipients. Circulatio 1989;79:76-82.

35 Fallen EL, Kamath MV, Ghista DN, Fitchett D. Spectra analysis of heart rate variability following human heart transplantation: evidence for functional reinnervation. ¥ Auton Nerv Syst 1988;23:199-206.

36 Zbilut TP, Murdock DK, Lawson L, Lawless CE, Von Dreele MM, Porges SW. Use of power spectral analysis of respiratory sinus arrhythmia to detect graft rejection. respiratory sinus arrhythmia to

37 Lear Electrocardiographic behavior of recipient and donor atria after human heart transplantation. Am $f$ Cardiol atria after hum

38 Mohanty PK, Thames MD, Arrowood JA, Sowers JR McNamara C, Szentpetery S. Impairment of cardiopulmonary baroreflex after cardiac transplantation in humans. Circulation 1987;75:914-2

39 Scherrer U, Vissing SF, Morgan BJ, Rollins JA, Tindal RSA, Ring S, et al. Cyclosporine-induced sympathetic activation and hypertension after heart transplantation. N Engl F Med 1990;323:693-9.

40 Airaksinen KEJ, Ikaheimo MJ, Takkunen JT. Heart rate after coronary artery bypass grafting. Am $\mathcal{F}$ Cardiol 1987 ; 60:1395-7.

41 Miyazaky T, Pride HP, Zipes DP. Prostaglandins in the pericardial fluid modulate neural regulation of cardiac
electrophysiologic properties. Circ Res 1990;66:163-75.

42 Ferguson DW, Berg WJ, Sanders JS, Roach PJ, Kempf JS Kienzle MG. Sympathoinhibitory responses to digitalis Kienzle MG. Sympathoinhibitory responses to digitalis
glycosides in heart failure patients. Circulation 1989; glycosides

43 Flapan AD, Nolan J, Neilson JMM, Ewing DJ. Effect of Captopril on cardiac parasympathetic activity in chronic cardiac failure secondary to coronary artery disease. $\operatorname{Am} \mathcal{F}$ Cardiol 1992;69:532-5. 